\title{
PRODUTIVIDADE E COMPOSIÇÃO BROMATOLÓGICA DE Brachiaria spp., NO ALTO VAĽE DO JEQUITINHONHA ${ }^{1}$
}

\author{
Productivity and bromatological composition of \\ Brachiaria spp. in the Higher Jequitinhonha Valley ${ }^{1}$ \\ Rosana Cristina Pereira ${ }^{2}$, Karina Guimarães Ribeiro ${ }^{3}$, Odilon Gomes Pereira ${ }^{4}$, \\ Janaina de Lima Silva ${ }^{4}$, Jakline Magela dos Santos ${ }^{4}$, João Paulo Sampaio Rigueira ${ }^{4}$
}

\begin{abstract}
RESUMO
Avaliaram-se a produtividade de matéria seca (MS), proporção de lâminas e composição bromatológica de Brachiaria spp., colhidas com 42 dias de rebrotação, em Diamantina, MG. Para a determinação dos teores de MS, PB, FDN, FDA e lignina utilizaramse o esquema em parcelas subsubdivididas, no DIC, com quatro repetições. Nas parcelas foram distribuídas as cultivares Basilisk, Marandu, Xaraés, Llanero e B. humidicola comum; nas subparcelas, dois cortes, e, nas subsubparcelas, dois anos experimentais. A produção de MS total e a proporção de lâminas foram analisadas em esquema de parcelas subdivididas, com espécies/cultivares nas parcelas e anos nas subparcelas. A produção de MS no segundo ano (3 cortes) foi mais alta que no primeiro ( 2 cortes), destacandose as cultivares Basilisk, Xaraés e Llanero. De modo geral, as cultivares apresentaram teores satisfatórios de PB, mais altos no segundo ano. Os teores de FDN foram mais baixos no segundo ano e os de lignina mais baixos no primeiro ano. As cultivares Xaraés e Marandu destacam-se pela elevada proporção de folhas e apresentam composição bromatológica semelhante a da cultivar Basilisk. Associandose a composição bromatológica com a produtividade de MS, recomendam-se as cultivares Xaraés e Basilisk para as condições do Alto Vale do Jequitinhonha.
\end{abstract}

Termos para indexação: FDN, FDA, lignina, proporção de lâminas, proteína bruta.

\section{ABSTRACT}

Dry matter production, proportion of leaf blades and chemical composition of Brachiaria spp. harvested at intervals of 42 days of regrowth, in Diamantina, MG were evaluated. The DM, CP, NDF, ADF and lignin contents were analyzed in a split-split plot completely randomized design, with four replicates. Five cultivars of Brachiaria were distributed in the plots, two cuts in the splitplot, and two experimental years in the split-split plot. The dry matter production and the proportion of leaf blades were analyzed in a split plot completely randomized design, with cultivars in the plots and years in the subplots. The dry matter production in the second year ( 3 cuts) was higher than in the first ( 2 cuts), especially with the cultivars Basilisk, Xaraés and Llanero. Generally, the cultivars presented satisfactory levels of $\mathrm{CP}$, with higher values in the second year. The contents of NDF were lower in the second year and the lowest levels of lignin were in the first year. Cultivars Xaraés and Marandu stand out for the high proportion of leaves and presented chemical composition similar to the Basilisk cultivar. Based on the chemical composition and dry matter production, Xaraés and Basilisk cultivars are recommended for cultivation in the Jequitinhonha High Valley.

Index terms: NDF, ADF, lignin, leaf blade, crude protein.

(Recebido em 13 de janeiro de 2009 e aprovado em 13 de julho de 2009)

\section{INTRODUÇÃO}

O Vale do Jequitinhonha é povoado por aproximadamente um milhão de pessoas, distribuídas em mais de 80 municípios, com características distintas. Contudo, a diversidade sociocultural da região tende a ser negligenciada pela difusão de informações que predominantemente salientam suas mazelas. A diversidade regional remonta às origens históricas (Cordeiro, 2009). Segundo Brasil (1997), os núcleos urbanos da bacia do rio Jequitinhonha resultaram de um processo histórico de ocupação territorial determinado pela atividade garimpeira e com a decadência das atividades mineradoras a agropecuária assumiu papel central na economia. A região do Alto Vale do Jequitinhonha, onde se encontra o município de Diamantina, possui características edafoclimáticas que impõem limitações à adaptação de algumas espécies forrageiras e há escassez de informações sobre o potencial de espécies e/ou cultivares nessa região. Espécies forrageiras do gênero Brachiaria se destacam pela adaptação a variadas condições de clima, solo e

${ }^{1}$ Projeto parcialmente financiado pela Fundação de Amparo à Pesquisa do Estado de Minas Gerais/FAPEMIG 2Universidade Federal dos Vales do Jequitinhonha e Mucuri/UFVJM - Campus II J.K. - Rodovia MGT 367 - km 583 - 5000 - Bairro Alto da Jacuba 39100-000 - Diamantina, MG - rosanac pereira@yahoo.com.br

${ }^{3}$ Universidade Federal dos Vales do Jequitinhonha e Mucuri/UFVJM - Departamento de Zootecnia/DZO - Diamantina, MG

${ }^{4}$ Universidade Federal de Viçosa/UFV - Departamento de Zootecnia/DZO - Viçosa, MG 
manejo. São plantas que apresentam alta produção de matéria seca, boa adaptabilidade, facilidade de estabelecimento, persistência, bom valor nutritivo e crescimento adequado durante a maior parte do ano, inclusive no período seco (Costa et al., 2005). As espécies de Brachiaria podem representar opção viável para os pecuaristas da região, haja vista que grande parte dos solos é do tipo Neossolo Quartzarênico, de baixa fertilidade. A composição bromatológica pode ser utilizada como variável indicativa do valor nutritivo das espécies forrageiras, toda,via é dependente de características genéticas da planta e de características ambientais. De acordo com Soest (1994) o valor nutritivo é influenciado pela fertilidade do solo, condições climáticas, idade fisiológica e manejo ao qual a planta está submetida. Característica como maior proporção de lâminas foliares é desejável em uma espécie forrageira, uma vez que as folhas apresentam melhor valor nutritivo que os colmos (Forbes \& Hodgson, 1985). Objetivou-se avaliar a produtividade de MS, a proporção de lâminas e a composição bromatológica de Brachiaria spp. colhidas em intervalos de 42 dias de rebrotação, em Diamantina, MG, no Alto Vale do Jequitinhonha.

\section{MATERIAL E MÉTODOS}

O experimento foi conduzido no Setor de Forragicultura do DZO da Faculdade de Ciências Agrárias, Campus II, da Universidade Federal dos Vales do Jequitinhonha e Mucuri/UFVJM, em Diamantina, região do Alto Vale do Jequitinhonha, MG. A temperatura média anual acusa pouca variação, situando-se na faixa de 21 a $24^{\circ} \mathrm{C}$. Segundo Brasil (1997), o mês mais quente é fevereiro e o mais frio é junho. As zonas serranas, atenuadas pelo efeito da altitude, apresentam temperaturas mais amenas, contrapondo-se às áreas deprimidas (vales), onde os índices térmicos são mais elevados. O Campus II situa-se a 1400 m de altitude, com coordenadas $18^{\circ} 9^{\prime} \mathrm{S}$ de latitude e $43^{\circ} 21^{\prime}$ WGR. O clima é mesotérmico, Cwb na classificação de Köppen, com verões brandos e úmidos, invernos mais frescos e secos e curtas transições realizadas nos meses de maio e setembro. Os dados climáticos registrados durante o período experimental encontram-se na Tabela 1.

O solo da área experimental é do tipo Neossolo Quartzarênico Órtico típico (Empresa Brasileira de Pesquisa Agropecuária - Embrapa, 2006) e em novembro/2006, outubro/2007 e março/2008, foi amostrado na camada de 0-20 cm, retirando-se uma amostra de cada parcela, obtendose uma amostra composta, e os resultados das análises encontram-se na Tabela 2.

Utilizou-se o esquema em parcelas subsubdivididas, no delineamento inteiramente casualizado (DIC), em virtude da área homogênea, com quatro repetições. Nas parcelas foram distribuídas $B$. decumbens Stapf. cv. Basilisk; Brachiaria brizantha (Hochst.) Stapf. cv. Marandu e cv. Xaraés; B. humidicola (Rendle) Schweickt cv. Llanero e B. humidicola (Rendle) Schweickt; nas subparcelas, dois cortes, e, nas subsubparcelas, dois anos experimentais. A produção de MS total (PMS) e a proporção de lâminas foram analisadas em esquema de parcelas subdivididas,

Tabela 1 - Médias das temperaturas (T) mínimas, médias e máximas, umidade relativa do ar (UR) e precipitação pluvial acumulada (PPA) durante o período experimental, nos dois anos agrícolas, em Diamantina, no Alto Vale do Jequitinhonha, MG.

\begin{tabular}{ccccccc}
\hline Ano & Período & $\mathrm{T} \mathrm{min}\left({ }^{\circ} \mathrm{C}\right)$ & $\mathrm{T} \operatorname{med}\left({ }^{\circ} \mathrm{C}\right)$ & $\mathrm{T} \max \left({ }^{\circ} \mathrm{C}\right)$ & $\mathrm{UR}(\%)$ & $\mathrm{PPA}(\mathrm{mm})$ \\
\hline 1 & $18 / 12 / 06$ a $12 / 03 / 07$ & 17,0 & 20,4 & 26,0 & 78,5 & 461,4 \\
2 & $09 / 11 / 07$ a $07 / 03 / 08$ & 16,2 & 20,5 & 26,0 & 77,0 & 734,1 \\
\hline
\end{tabular}

Fonte: INMET (2008).

Tabela 2 - Atributos químicos do solo da área experimental, em Diamantina, no Alto Vale do Jequitinhonha, MG.

\begin{tabular}{|c|c|c|c|c|c|c|c|c|c|c|c|c|}
\hline \multirow[t]{2}{*}{ Ano } & \multirow{2}{*}{$\begin{array}{c}\mathrm{pH} \\
\text { água }\end{array}$} & $\mathrm{P}$ & $\mathrm{K}$ & $\mathrm{Ca}$ & $\mathrm{Mg}$ & $\mathrm{Al}$ & $\mathrm{H}+\mathrm{Al}$ & SB & $\mathrm{T}$ & $\mathrm{V}$ & $\mathrm{m}$ & M.O. \\
\hline & & \multicolumn{2}{|c|}{$\mathrm{mg} / \mathrm{dm}^{3}$} & \multicolumn{6}{|c|}{$\mathrm{cmol}_{\mathrm{c}} / \mathrm{dm}^{3}$} & \multicolumn{2}{|c|}{$\%$} & $\mathrm{dag} / \mathrm{kg}$ \\
\hline 2006 & 5,6 & 1,7 & 18 & 0,5 & 0,3 & 0,3 & 2,7 & 0,8 & 3,5 & 23 & 25 & 0,7 \\
\hline 2007 & 5,0 & 2,8 & 42 & 1,5 & 0,4 & 0,3 & 5,4 & 2,0 & 7,0 & 27 & 13 & 1,7 \\
\hline 2008 & 5,5 & 1,8 & 32 & 0,4 & 0,3 & 0,2 & 5,5 & 0,9 & 6,4 & 13 & 20 & 0,5 \\
\hline
\end{tabular}

SB: soma de bases; T: capacidade de troca de cátions a pH 7,0; V: saturação por bases; m: saturação por alumínio; M.O.: matéria orgânica. 
com cultivares nas parcelas e anos nas subparcelas, no DIC, com quatro repetições. A produção de MS do primeiro ano foi obtida pelo somatório de dois cortes, uma vez que as plantas não se desenvolveram o suficiente para permitir um terceiro corte, e, no segundo ano, obtida pelo somatório de três cortes. A proporção de lâminas foi avaliada somente no segundo corte, em cada ano. As forrageiras estavam estabelecidas desde 2003, porém, sem manejo adequado de adubação. $\mathrm{O}$ experimento iniciou-se em 18 de dezembro de 2006, quando foi realizado um corte de uniformização e aplicados $350 \mathrm{~kg} / \mathrm{ha}$ de calcário, $100 \mathrm{~kg} / \mathrm{ha}$ de $\mathrm{P}_{2} \mathrm{O}_{5}, 30 \mathrm{~kg} /$ ha/corte de $\mathrm{N}$ e $30 \mathrm{~kg} / \mathrm{ha} /$ corte de $\mathrm{K}_{2} \mathrm{O}$, em cobertura, em

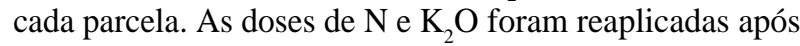
o primeiro e segundo cortes, executados em intervalos de 42 dias, no período chuvoso, totalizando aplicação anual de $90 \mathrm{~kg} / \mathrm{ha}$ de $\mathrm{N}$ e $90 \mathrm{~kg} / \mathrm{ha}$ de $\mathrm{K}_{2} \mathrm{O}$. No segundo, ano efetuou-se o mesmo manejo de adubação do primeiro ano. As parcelas experimentais possuíam área de $26,25 \mathrm{~m}^{2} \mathrm{e}$ as amostragens das forrageiras foram realizadas em área útil de 2,25 $\mathrm{m}^{2}$, utilizando-se um quadrado de 1,5 x 1,5 m. Os cortes foram realizados manualmente, com auxílio de cutelos, a $15 \mathrm{~cm}$ da superfície do solo. As amostras de plantas foram pesadas, submetidas à pré-secagem a $60^{\circ} \mathrm{C}$, durante 72 horas, em estufa com ventilação forçada de ar e moídas em moinho de facas tipo "Willey", com peneira de $1 \mathrm{~mm}$. Determinaram-se a produtividade de MS (kg/ha/ano) e os teores MS, proteína bruta (PB), fibra em detergente neutro (FDN), fibra em detergente ácido (FDA) e lignina, na MS a $105^{\circ} \mathrm{C}$, segundo Silva \& Queiroz (2002). No segundo corte de cada ano, efetuados em março de 2007 e janeiro de 2008, uma parte da amostra foi utilizada para estimativa da porcentagem de lâminas foliares, cortandose as lâminas na região da lígula e separando-as do resto do material. Todas as amostras de lâminas e colmos foram pesadas e submetidas à pré-secagem a $60^{\circ} \mathrm{C}$. A partir do peso de amostras secas de lâminas e de colmos foi calculada a proporção da fração lâmina, para cada tratamento. Os dados foram submetidos à análise de variância e aos testes de médias "F" e de "Tukey", a 5\% de probabilidade, utilizando-se o programa SISVAR (Ferreira, 2008).

\section{RESULTADOS E DISCUSSÃO}

Não houve efeito da interação cultivar e ano para a produtividade de MS, porém verificaram-se efeitos de ano e de cultivar. No primeiro ano experimental, a produtividade de MS, média das cultivares, foi de $883,83 \mathrm{~kg} / \mathrm{ha}$ (somatório de dois cortes) e no segundo ano foi de 2336,03 kg/ha (somatório de três cortes). Assim, observa-se um incremento de aproximadamente, $164 \%$ na produção de MS de um ano para o outro. As produtividades de MS estão registradas na Tabela 3 .

Verifica-se mais alta produção para a cultivar Basilisk, em relação à Marandu e $B$. humidicola, porém, sem diferir das obtidas para Xaraés e Llanero. Entretanto, de modo geral, as produções de MS foram muito baixas, o que pode ser atribuído a vários fatores, como baixa fertilidade natural do solo, baixas doses utilizadas de $\mathrm{N} \mathrm{e}$ $\mathrm{K}_{2} \mathrm{O}$ após os cortes, distribuição irregular das chuvas e baixas temperaturas.

A análise de variância detectou efeito da interação dos fatores cultivar e ano para a proporção de lâminas foliares. Na Tabela 4 estão apresentados os valores dessa fração determinados para Brachiaria spp.

As cultivares Marandu e Xaraés destacaram-se pelas elevadas proporções de lâminas, semelhantes nos dois anos. Os valores registrados para a Marandu, 93,38 e 99,07\% no primeiro e segundo anos, respectivamente, foram superiores aos verificados por Gerdes et al. (2000) para essa cultivar, aos 35 dias de crescimento no verão, de 72,92\% de lâminas, e por Santos et al. (2003), de 89,01\%. Nesta pesquisa, a baixa fertilidade do solo pode ter contribuído para o mais lento crescimento das plantas, com menor alongamento dos colmos, refletindo na mais alta proporção de lâminas. No primeiro ano, 'Basilisk' apresentou mais alta proporção de lâminas (73,38\%) que B. humidicola e 'Llanero'. No segundo ano, 'Basilisk' apresentou baixa proporção de lâminas, sendo semelhante à $B$. humidicola, e 'Llanero' apresentou a mais baixa proporção de lâminas $(20,65 \%)$, tornando importante destacar que nesta ocasião B. humidicola e 'Llanero' estavam em pleno florescimento.

Não foi observado efeito da interação cultivar, corte e ano para os teores de PB. Entretanto, verificou-se efeito

Tabela 3 - Produtividade de matéria seca (kg/ha/ano), média de dois anos de Brachiaria spp., em Diamantina, no Alto Vale do Jequitinhonha, MG.

\begin{tabular}{ccccc}
\hline Basilisk & Xaraés & Marandu & Llanero & B. humidicola \\
\hline \multicolumn{5}{c}{ PMS (kg/ha/ano) } \\
\hline $2037,65 \mathrm{a}$ & $1926,70 \mathrm{ab}$ & $1200,34 \mathrm{bc}$ & $1733,20 \mathrm{abc}$ & $1151,77 \mathrm{c}$ \\
\hline
\end{tabular}

Médias seguidas pela mesma letra não diferem pelo teste de Tukey $(\mathrm{P}>0,05)$. 
das interações cultivar e corte e cultivar e ano, cujos resultados estão registrados nas Tabelas 5 e 6.

De modo geral, os teores de PB no primeiro corte foram elevados e 'Basilisk' apresentou o mais alto teor, não diferindo de B. humidicola e 'Marandu'. A cultivar Llanero foi a menos protéica $(9,6 \%)$, mas com teor protéico satisfatório, em se tratando de Brachiaria. No segundo corte, as cultivares Xaraés e Marandu foram as mais protéicas, consequência da alta proporção de lâminas foliares apresentadas por essas cultivares. Os teores de PB foram mais baixos nesse corte, em relação aos obtidos no primeiro, exceto para 'Xaraés'. A cultivar Llanero apresentou o teor mais baixo de PB $(6,17 \%)$, registrado no segundo corte do segundo ano, que pode ser decorrente da baixa proporção de lâminas apresentada por essa cultivar. Considerando-se que para as atividades normais das bactérias ruminais são necessários de 6 a 8\% de PB na MS (Mertens, 1994), todas as cultivares atenderiam à exigência. As cultivares apresentaram teores satisfatórios de $\mathrm{PB}$, destacando-se, no primeiro ano 'Xaraés' e 'Marandu' (Tabela 6). No segundo ano, 'Basilisk' (13,28\%) apresentou o mais alto teor, não diferindo da cultivar Marandu (12,78\%). Observa-se, para todas as cultivares, maior teor protéico no segundo ano. Botrel et al. (1999) registraram, para a B. brizantha, $B$. decumbens e $B$. humidicola, teores de 12,3; 10,4 e 8,6\% de $\mathrm{PB}$, respectivamente, aos 35 dias de crescimento, durante o período das chuvas, no Sul de Minas.

Para os teores de FDN, houve efeito da interação cultivar e corte e efeito de ano. Os valores obtidos estão apresentados na Tabela 7. No primeiro corte, 'Basilisk' apresentou menor teor de $\operatorname{FDN}(60,35 \%)$, não diferindo das cultivares Marandu e Xaraés. A cv. Llanero apresentou o maior teor $(73,81 \%)$, não diferindo de $B$. humidicola. No segundo corte, as cultivares Xaraés e Marandu apresentaram os mais baixos teores de FDN, o que pode ser justificado pela maior proporção de lâminas apresentada por essas cultivares, porém não diferiram da Basilisk. Os teores de FDN foram semelhantes entre

Tabela 4 - Proporções de lâminas foliares de Brachiaria spp. em Diamantina, no Alto Vale do Jequitinhonha, MG.

\begin{tabular}{cccccc}
\hline & Basilisk & Xaraés & Marandu & Llanero & B. humidicola \\
\hline Ano & & \multicolumn{5}{c}{ Lâminas foliares (\%) } \\
\hline $1(2006 / 07)$ & $73,38 \mathrm{Ab}$ & $94,60 \mathrm{Aa}$ & $93,38 \mathrm{Aa}$ & $48,76 \mathrm{Ac}$ & $55,37 \mathrm{Ac}$ \\
$2(2007 / 08)$ & $38,26 \mathrm{Bb}$ & $98,74 \mathrm{Aa}$ & $99,07 \mathrm{Aa}$ & $20,65 \mathrm{Bc}$ & $49,33 \mathrm{Ab}$ \\
\hline
\end{tabular}

Médias seguidas pela mesma letra maiúscula nas colunas e minúscula nas linhas não diferem pelos testes $\mathrm{F}$ e de Tukey (P>0,05), respectivamente.

Tabela 5 - Teores médios de proteína bruta (PB) de Brachiaria spp., em Diamantina, no Alto Vale do Jequitinhonha, MG.

\begin{tabular}{cccccc}
\hline & Basilisk & Xaraés & Marandu & Llanero & B. humidicola \\
\hline Corte & & PB $(\%$ na MS $)$ \\
\hline 1 & $12,45 \mathrm{Aa}$ & $10,56 \mathrm{Abc}$ & $11,73 \mathrm{Aab}$ & $9,60 \mathrm{Ac}$ & $11,74 \mathrm{Aab}$ \\
2 & $8,44 \mathrm{Bb}$ & $10,37 \mathrm{Aa}$ & $10,23 \mathrm{Ba}$ & $6,17 \mathrm{Bc}$ & $7,89 \mathrm{Bb}$ \\
\hline
\end{tabular}

Médias seguidas pela mesma letra maiúscula nas colunas e minúscula nas linhas não diferem pelos testes $\mathrm{F}$ e de Tukey $(\mathrm{P}>0,05)$, respectivamente.

Tabela 6 - Teores médios de proteína bruta (PB) de Brachiaria spp., em Diamantina, no Alto Vale do Jequitinhonha, MG.

\begin{tabular}{cccccc}
\hline & Basilisk & Xaraés & Marandu & Llanero & B. humidicola \\
\hline Ano & & PB $(\%$ na MS $)$ \\
\hline 1 & $7,61 \mathrm{Bb}$ & $9,19 \mathrm{Ba}$ & $9,17 \mathrm{Ba}$ & $7,00 \mathrm{Bb}$ & $7,76 \mathrm{Bb}$ \\
2 & $13,28 \mathrm{Aa}$ & $11,75 \mathrm{Ab}$ & $12,78 \mathrm{Aab}$ & $8,77 \mathrm{Ac}$ & $11,86 \mathrm{Ab}$ \\
\hline
\end{tabular}

Médias seguidas pela mesma letra maiúscula nas colunas e minúscula nas linhas não diferem pelos testes $\mathrm{F}$ e de Tukey (P>0,05), respectivamente. 
Marandu e Xaraés, entretanto, Costa et al. (2009) obtiveram para o capim-xaraés menor teor de FDN em relação a outras cultivares de B. brizantha. Benett et al. (2008) observaram que o teor de FDN na cv. Marandu variou em função dos cortes, sendo maior no terceiro corte $(70,45 \%)$, o qual foi efetuado aos 34 dias de crescimento.

A cultivar Basilisk e $B$. humidicola apresentaram teor mais elevado de FDN no segundo corte, não sendo observadas diferenças entre cortes nas demais cultivares. $\mathrm{O}$ teor de FDN é um importante parâmetro que define a qualidade da forragem, sendo que valores acima de $60 \%$ correlacionam-se negativamente com o consumo voluntário de MS pelos animais (Soest, 1994). Verifica-se na Tabela 7 que todas as cultivares apresentaram teores médios superiores a 60\% de FDN,e para Costa et al. (2009), isso indica que o consumo voluntário dessas forrageiras em pastejo poderia ser limitado no caso de uma pressão de pastejo alta, que reduziria a seletividade dos bovinos. Santos et al. (2003) verificaram para a B. brizantha cv. Marandu, teor de 74,80\% de FDN aos 35 dias de crescimento.

O teor de FDN foi influenciado pelo fator ano, registrando-se teores mais baixos no segundo ano $(67,45 \%)$, em comparação ao primeiro ano $(69,95 \%$ na MS). No segundo ano, a qualidade da forragem produzida foi superior à do primeiro, uma vez que os teores médios de PB foram mais altos e os de FDN mais baixos.

Verificou-se efeito da interação cultivar, corte e ano $(\mathrm{P}<0,05)$ para os teores de FDA, cujos resultados estão apresentados na Tabela 8.

No primeiro corte do primeiro ano, as cultivares apresentaram teores semelhantes de FDA, com média de $40,33 \%$. No segundo corte 'Xaraés' proporcionou o menor teor $(30,84 \%)$ e 'Basilisk' o maior $(51,22 \%)$, porém não diferindo de $B$. humidicola e da cultivar Llanero. No primeiro ano, a cultivar Marandu e $B$. humidicola não apresentaram diferenças nos teores de FDA entre cortes, enquanto as cultivares Basilisk e Llanero apresentaram aumento e Xaraés redução, no segundo corte. No segundo ano, não foram detectadas diferenças $(\mathrm{P}>0,05)$ entre cultivares e cortes (Tabela 8). Avaliando a B. brizantha cv. Marandu, Santos et al. (2003) verificaram teor de 40,22\% de FDA, aos 35 dias de crescimento. Costa et al. (2007) observaram, para 'Marandu', teores de 34,0 e $36,0 \%$ de FDA aos 30 e 60 dias, respectivamente, e Benett et al. (2008) um teor médio de $34,06 \%$, com cortes realizados aos 30 e 34 dias.

Para os teores de lignina, verificou-se efeito da interação cultivar e corte (Tabela 9) e efeito de ano, sendo que no primeiro ano $(4,86 \%)$ os teores médios foram mais baixos que no segundo ano $(6,18 \%)$.

Tabela 7 - Teores médios de fibra em detergente neutro (FDN) de Brachiaria spp., em Diamantina, no Alto Vale do Jequitinhonha, MG.

\begin{tabular}{cccccc}
\hline & Basilisk & Xaraés & Marandu & Llanero & B. humidicola \\
\hline Corte & & FDN $(\%$ na MS) & \\
\hline 1 & $60,35 \mathrm{Bc}$ & $65,72 \mathrm{Abc}$ & $65,36 \mathrm{Abc}$ & $73,81 \mathrm{Aa}$ & $68,10 \mathrm{Bab}$ \\
2 & $71,63 \mathrm{Aab}$ & $66,06 \mathrm{Ab}$ & $66,54 \mathrm{Ab}$ & $76,00 \mathrm{Aa}$ & $73,44 \mathrm{Aa}$ \\
\hline
\end{tabular}

Médias seguidas pela mesma letra maiúscula nas colunas e minúscula nas linhas não diferem pelos testes $\mathrm{F}$ e de Tukey $(\mathrm{P}>0,05)$, respectivamente.

Tabela 8 - Teores de fibra em detergente ácido (FDA) de Brachiaria spp., em Diamantina, no Alto Vale do Jequitinhonha, MG.

\begin{tabular}{lcccc}
\hline & \multicolumn{3}{c}{ Ano 1} & \multicolumn{2}{c}{ Ano 2} \\
\cline { 2 - 5 } Cultivar & Corte 1 & Corte 2 & Corte 1 & Corte 2 \\
\cline { 2 - 4 } & & \multicolumn{2}{c}{ FDA (\% na MS) } \\
\hline Basilisk & $36,22 \mathrm{Ab}$ & $51,22 \mathrm{Aa}$ & $33,64 \mathrm{Aa}$ & $39,12 \mathrm{Aa}$ \\
Xaraés & $38,53 \mathrm{Aa}$ & $30,84 \mathrm{Cb}$ & $37,71 \mathrm{Aa}$ & $40,84 \mathrm{Aa}$ \\
Marandu & $41,23 \mathrm{Aa}$ & $41,18 \mathrm{Ba}$ & $38,61 \mathrm{Aa}$ & $38,78 \mathrm{Aa}$ \\
Llanero & $41,76 \mathrm{Ab}$ & $49,28 \mathrm{ABa}$ & $40,59 \mathrm{Aa}$ & $44,79 \mathrm{Aa}$ \\
B. humidicola & $43,91 \mathrm{Aa}$ & $49,52 \mathrm{ABa}$ & $35,30 \mathrm{Aa}$ & $40,05 \mathrm{Aa}$ \\
\hline
\end{tabular}

Médias seguidas pela mesma letra maiúscula nas colunas e minúscula nas linhas não diferem pelos testes de Tukey e $\mathrm{F}(\mathrm{P}>0,05)$, respectivamente. 
Tabela 9 - Teores médios de lignina (\%) de Brachiaria spp., em Diamantina, no Alto Vale do Jequitinhonha, MG.

\begin{tabular}{cccccc}
\hline & Basilisk & Xaraés & Marandu & Llanero & B. humidicola \\
\hline Corte & & \multicolumn{5}{c}{ Lignina (\% na MS) } \\
\hline 1 & $4,63 \mathrm{Ba}$ & $5,21 \mathrm{Aa}$ & $5,48 \mathrm{Aa}$ & $4,49 \mathrm{Ba}$ & $5,10 \mathrm{Ba}$ \\
2 & $6,93 \mathrm{Aa}$ & $4,44 \mathrm{Ab}$ & $5,02 \mathrm{Ab}$ & $7,06 \mathrm{Aa}$ & $6,86 \mathrm{Aa}$ \\
\hline
\end{tabular}

Médias seguidas pela mesma letra maiúscula nas colunas e minúscula nas linhas não diferem pelos testes $\mathrm{F}$ e de Tukey $(\mathrm{P}>0,05)$, respectivamente.

As cultivares de Brachiaria apresentaram teores semelhantes de lignina no primeiro corte, com valor médio de 4,98\%. No segundo corte 'Xaraés' $(4,44 \%)$ e 'Marandu' $(5,02 \%)$ apresentaram teores inferiores às demais, o que comprova a importância da utilização de cultivares com maior proporção de lâminas foliares para a produção de forragem de melhor valor nutritivo. As cultivares Xaraés e Marandu apresentaram teores semelhantes de lignina nos dois cortes, enquanto as cultivares Basilisk e Llanero e B. humidicola apresentaram teores inferiores no primeiro corte. A lignina é um polímero fenólico que se associa aos carboidratos estruturais, celulose e hemicelulose, durante o processo de formação da parede celular, alterando significativamente a digestibilidade desses carboidratos das forragens (Norton, 1982), sendo desejáveis, portanto, teores mais baixos dessa fração.

\section{CONCLUSÕES}

As cultivares Xaraés e Marandu destacam-se pela elevada proporção de folhas e apresentam composição bromatológica semelhante a da cultivar Basilisk. Associando-se a composição bromatológica e a produtividade de MS, recomendam-se as cultivares Xaraés e Basilisk para as condições do Alto Vale do Jequitinhonha.

\section{REFERÊNCIAS BIBLIOGRÁFICAS}

BOTREL, M.A.; ALVIM, M.J.; XAVIER, D.F. Avaliação de gramíneas forrageiras na Região Sul de Minas Gerais. Pesquisa Agropecuária Brasileira, Brasília, v.34, n.4, p.683-689, abr. 1999.

BRASIL. Ministério do Planejamento e Orçamento. Fundação Instituto Brasileiro de Geografia e Estatística. Diagnóstico ambiental da bacia do rio Jequitinhonha. Salvador: IBGE/Diretoria de Geociências, 1997.

CORDEIRO, E. do N. Vale do Jequitinhonha: entre a carência e a riqueza. Revista de Artes e Humanidades. Santo André, SP, v.4, maio/out., 2009. Disponível em: http://

Lwww.revistacontemporaneos.com.
COSTA, K.A. de P.; OLIVEIRA, I.P.; FAQUIN, V. Intervalo de corte na produção de massa seca e composição químico-bromatológica da Brachiaria brizantha cv. MG-5. Ciência e Agrotecnologia, Lavras, v.31, n.4, p.1197-1202, jul./ago. 2007.

COSTA, K.A. de P.; ROSA, B.; OLIVEIRA, I.P. de, et al. Efeito da estacionalidade na produção de matéria seca e composição bromatológica da Brachiaria brizantha cv. Marandu. Ciência Animal Brasileira, Goiânia, v. 6, n. 3, p. 187-193, 2005.

\section{EMPRESA BRASILEIRA DE PESQUISA}

AGROPECUÁRIA. Centro Nacional de Pesquisa de Solos. Sistema brasileiro de classificação de solos. 2.ed. Rio de Janeiro, 2006. 306p.

FERREIRA, D.F. SISVAR: um programa para análises e ensino de estatística. Revista Symposium, Lavras, v.6, p.36-41, 2008.

FORBES, T.D.A.; HODGSON, J. Comparative studies of the influence of sward conditions on the ingestive behaviour of cows and sheep. Grass and Forage Science, v.40, p.69-77, 1985.

GERDES, L.; WERNER, J.C.; COLOZZA, M.T.; CARVALHO, D.D.; SCHAMMASS, E.A. Avaliação de características agronômicas e morfológicas das gramíneas forrageiras Marandu, Setária e Tanzânia aos 35 dias de crescimento nas estações do ano. Revista Brasileira de Zootecnia, Viçosa, v.29, n.4, p.947-954, jul./ago. 2000.

INSTITUTO NACIONAL DE METEOROLOGIA.

INMET. Monitoramento das Estações Automáticas, Diamantina, MG. Disponível em: <http:// Www.inmet.gov.br//>. Acesso em: 10 mar. 2008.

MERTENS, D.R. Regulation of forage intake. In: FAHEY JUNIOR, G.C. (Ed.). Forage quality, evaluation and utilization. Madison: American Society of Agronomy, 1994. p.450-493. 
NORTON, B.W. Differences between species in forrage quality. In: HACKER, J.B. (Ed.). Nutritional limits to animal production from pastures. Farnham Royal: Commonwealth Agricultural Bureaux, 1982. p.89-110.

SANTOS, M.V.F.; DUBEUX JÚNIOR, J.C.B.; SILVA, M.C.; SANTOS, S.F.; FERREIRA, R.L.C.; MELLO, A.C.L.; FARIAS, I.; FREITAS, E.V. Produtividade e composição química de gramíneas tropicais na Zona da Mata de Pernambuco. Revista Brasileira de Zootecnia, Viçosa. v.32, n.4, p.821-827, jul./ago. 2003.

SILVA, D.J.; QUEIRÓZ, A.C. Análise de Alimentos: métodos químicos e biológicos. 3.ed. Viçosa, MG: UFV, 2002. 235p.

SOEST, P.J. van. Nutritional ecology of the ruminant. 2.ed. Ithaca: Cornell University, 1994. 446p. 